\title{
RETRACTED ARTICLE: Enhancement of doxorubicin efficacy through suppression of serine synthesis in triple-negative breast cancer
}

\author{
Feng Wang • Yong Yang
}

Received: 7 November 2014/ Accepted: 13 January 2015/Published online: 24 January 2015

(C) Springer Science+Business Media New York 2015

This article has been retracted at the request of the corresponding author due to submission of his article for publication without internal review and approval from his institution (Houston Methodist Research Institute).

F. Wang

Department of Gastroenterology, The Tenth People's Hospital of Shanghai, Tongji University, Shanghai 200072, People's

Republic of China

F. Wang · Y. Yang $(\bowtie)$

Department of Nanomedicine, Houston Methodist Research

Institute, Houston, TX 77030, USA

e-mail: lovegate5@yahoo.com

Y. Yang

Laboratory of Metabolic Disease Research and Drug

Development, China Medical University,

Shenyang 110001, Liaoning, People's Republic of China 